\title{
Hubungan Jenis Organ dan Jumlah Organ yang Mengalami Gangguan dengan Prognosis dan Outcome pada Pasien Malaria Falciparum Berat di RSUP Dr. M. Djamil Padang
}

\author{
Riche Anggresti ${ }^{1}$, Nuzulia Irawati ${ }^{2}$, Roza Kurniati ${ }^{3}$
}

\begin{abstract}
Abstrak
Malaria merupakan penyakit tropik infeksi yang dapat menyebabkan kematian. Angka kematian malaria meningkat terutama pada malaria berat karena progresifitas penyakit sangat cepat menyebabkan kematian antara 1872 jam. Tujuan penelitian ini adalah untuk mengetahui hubungan jenis organ dan jumlah organ yang mengalami gangguan dengan prognosis dan out come pada pasien malaria falciparum berat. Jenis penelitian ini menggunakan observasional analitik dengan desain cross sectional yang dilaksanakan pada bulan Januari 2014 sampai Maret 2014 di bagian Rekam Medik RSUP Dr. M. Djamil Padang. Populasi penelitian ini adalah pasien malaria falciparum sebanyak sebanyak 37 orang dengan sampel sebanyak 13 orang dari populasi yang memenuhi kriteria sampel malaria falciparum berat. Analisis data menggunakan uji chi square dengan $p<0,05$. Hasil penelitian didapatkan sebagian besar $(92,3 \%)$ pasien malaria falciparum berat mengalami gangguan organ, dimana jenis organ yang mengalami gangguan paling banyak $(68,75 \%)$ adalah hati dan masih terdapat pasien yang mengalami gangguan tiga organ sebanyak $8,3 \%$. Dapat disimpulkan bahwa terdapat hubungan yang bermakna antara adanya gangguan organ dengan prognosis $(p=0,03)$, pasien malaria falciparum berat dengan gangguan organ otak, hati, limpa dan ginjal, dengan satu jenis organ atau lebih akan mengalami prognosis buruk. Tidak terdapat hubungan antara adanya gangguan organ dengan outcome $(p=1,00)$, pasien yang mengalami malaria falciparum berat dengan gangguan organ otak dan hati keluar dalam keadaan sembuh (outcome sembuh), dan terdapat hubungan yang bermakna antara jumlah organ dengan outcome $(p=0,02)$. Sedikitnya jumlah sampel, diharapkan ada penelitian selanjutnya dengan populasi dan jumlah sampel yang lebih banyak.
\end{abstract}

Kata kunci: malaria falciparum berat, jenis organ, jumlah organ, prognosis, outcome.

\section{Abstract}

Malaria is tropic infection disease able to cause death. Mortality increases in severe malaria because progress of disease very quickly cause death in 18-72 hour. Target of this research is to know relation disfunction type organ and amount organ with prognosis and outcomes at severe malaria falciparum patient. This research was did use observational analytic with cross sectional design in January 2014 until March 2014 at the medical records RSUP M. Djamil Padang. Population in this research is malaria falcifarum patient there are 37 people with sampel is 13 one who represent population fulfilling criterion of sampel. Analysis by chi square with $p<0.05$. Result of research showed that most (92.3\%) severe malaria falciparum patient experience disfunction of organ, where disfunction type organ at most $(68.75 \%)$ is liver and still there are patient have three organ disfunction is $8.3 \%$. Inferential that there are relation/ having a meaning of between existence of organ disfunction with prognosis $(p=0.03)$, severe malaria falciparum patient with disfunction brain, liver, kidney and spleen, with one organ type or more will experience of ugly prognosis. There are was no relation between existence of disfunction organ with outcome $(p=1.00)$, severe malaria falciparum patient with disfunction brain and liver, go out in a state of recovering (outcome recover), and there are having relation between amount of disfunction organ with outcome $(p=0.02)$. At least the amount of sampel, expected by there is 
research hereinafter with amount and population of sampel which is more and RSUP M. Djamil Padang shoud completing medical records.

Keywords: severe malaria falciparum, type organ, amount of organ, prognosis, outcome

Affiliasi penulis : 1. Pendidikan Dokter FK UNAND (Fakultas Kedokteran Universitas Andalas Padang), 2. Bagian Parasitologi FK UNAND, 3. Bagian Penyakit Dalam FK UNAND

Korespondensi :Riche Anggresti, E-

mail:vdokter.ni_che@yahoo.com,Telp: 081266847947

\section{PENDAHULUAN}

Malaria merupakan penyakit infeksi pada daerah tropis yang disebabkan oleh sejenis parasit yaitu plasmodium yang menyerang eritrosit dan ditandai dengan adanya bentuk aseksual didalam darah yang ditularkan melalui gigitan nyamuk Anopheles betina yang mengandung parasit didalam kelenjer liurnya. Ada beberapa spesies plasmodium penyebab malaria pada manusia, namun Plasmodium falciparum merupakan spesies yang berbahaya karena dapat menyebabkan malaria berat dan kematian. Diperkirakan terdapat 400 juta kasus yang dilaporkan dari seluruh dunia dan menyebabkan lebih dari 1 juta kematian setiap tahun atau sekitar 1 dalam 30 detik. $^{1}$

Menurut WHO (2006), malaria berat didefinisikan sebagai infeksi Plasmodium falciparum dengan satu atau lebih komplikasi sebagai berikut ; malaria serebral, asidosis, anemia berat, gagal ginjal akut, hipoglikemi, syock, perdarahan, kejang dan hemoglobinuria. Prognosis malaria berat tergantung pada kecepatan pasien tiba dirumah sakit, kecepatan/ketepatan diagnosis dan pengobatan, jenis organ dan jumlah organ yang terlibat dalam komplikasi dan kepadatan parasit. ${ }^{2}$

Progresifitas penyakit malaria falciparum berat sangat cepat menyebabkan kematian antara 1872 jam, dimana prognosis malaria falciparum berat dengan kegagalan satu fungsi organ lebih baik dari pada kegagalan dua fungsi organ atau lebih. Mortalitas pada kegagalan tiga fungsi organ $>50 \%$ dan kegagalan lebih dari empat organ mencapai $75 \%$ atau lebih. $^{3,4}$

Penelitian di Minahasa pada malaria serebral didapatkan angka mortalitas mencapai $30,5 \%$, pasien dengan kelainan fungsi ginjal tanpa dialisis memberikan mortalitas $48 \%$ sedangkan pada pasien malaria billiosa dengan bilirubin $>3 \mathrm{mg} \%$ angka mortalitas $33 \%$. Pasien malaria cerebral yang disertai dengan kegagalan dua organ angka mortalitas 47,6\% dan dengan kegagalan tiga organ angka mortalitas mencapai $88,9 \%{ }^{5}$

Masih tingginya angka kematian malaria berat akibat kegagalan fungsi organ, penting diketahui jenis organ dan jumlah organ yang mengalami gangguan pada pasien malaria berat yang memperburuk prognosis dan meningkatkan angka mortalitas di RSUP M. Djamil Padang yang merupakan RS rujukan, penulis tertarik melakukan penelitian untuk mengetahui hubungan jenis organ dan jumlah organ yang mengalami gangguan dengan prognosis dan outcome pada pasien malaria falciparum berat.

\section{METODE}

Jenis penelitian ini menggunakan observasional analitik dengan desain cross sectional yang dilaksanakan pada bulan Januari 2014 sampai Maret 2014 di bagian Rekam Medik RSUP M. Djamil Padang. Populasi penelitian ini adalah pasien malaria falciparum sebanyak sebanyak 37 orang dengan sampel sebanyak 13 orang dari populasi yang memenuhi kriteria sampel malaria falciparum berat. Analisis data menggunakan uji chi square dengan $p<0,05$. Variabel bebasnya adalah jenis organ dan jumlah organ, sementara variable terikatnya adalah prognosis (baik, buruk) dan outcome (sembuh, meninggal).

\section{HASIL}

Hasil penelitian didapatkan sebagian besar (92,3\%) pasien malaria falciparum berat mengalami gangguan organ, dimana jenis organ yang mengalami gangguan paling banyak (68,75\%) adalah hati dan masih terdapat pasien yang mengalami gangguan tiga organ sebanyak $8,3 \%$.

Pada tabel 1 didapatkan ada Hubungan Adanya Gangguan Organ dengan Prognosis (nilai $p=$ $0,003)$, dimana pasien dengan gangguan organakan 
mengalami prognosis yang buruk, sedangkan pasien tanpa gangguan organ prognosisnya baik. Dalam penelitian ini semua pasien malaria falciparum berat dengan gangguan organ mengalami prognosis yang buruk.

Tabel 1. Hubungan Adanya Gangguan Organ dengan Prognosis pada Pasien Malaria Falciparum Berat yang Dirawat Inap di RSUP Dr.M. Djamil Padang pada Januari 2010 sampai Desember 2013

\begin{tabular}{lrrrrrrr}
\hline \multirow{2}{*}{$\begin{array}{c}\text { Gannguan } \\
\text { Organ }\end{array}$} & \multicolumn{4}{c}{ Prognosis } & \multicolumn{2}{c}{ Total } & \multirow{2}{*}{ P } \\
\cline { 2 - 6 } & $\mathbf{n}$ & $\%$ & $\mathbf{n}$ & $\%$ & $\mathbf{n}$ & $\%$ & \\
\cline { 2 - 6 } & & & & & & & \\
\hline Ada & 0 & 0 & 12 & 100 & 12 & 100 & 0,003 \\
Tidak & 1 & 100 & 0 & 0 & 1 & 100 & \\
\hline
\end{tabular}

Tabel 2. Hubungan Adanya Gangguan Organ dengan Outcome pada Pasien Malaria Falciparum Berat yang Dirawat Inap di RSUP M. Djamil Padang pada Januari 2010 sampai Desember 2013

\begin{tabular}{lrrrrrrrr}
\hline \multirow{2}{*}{$\begin{array}{l}\text { Gannguan } \\
\text { Organ }\end{array}$} & \multicolumn{4}{c}{ Outcome } & & Total & \\
\cline { 2 - 5 } & & Sembuh & \multicolumn{3}{c}{ Meninggal } & & P \\
\cline { 2 - 6 } & $\mathbf{n}$ & $\%$ & $\mathbf{n}$ & $\%$ & $\mathbf{n}$ & $\%$ & \\
\hline Ada & 11 & 92,3 & 0 & 0 & 11 & 100 & 1,00 \\
Tidak & 1 & 7,7 & 0 & 0 & 1 & 100 & \\
\hline
\end{tabular}

Pada tabel 2 didapatkan tidak ada Hubungan Adanya Gangguan Organ dengan Outcome (nilai $p=$ $1,00)$, artinya, pasien yang menderita gangguan organ masih dapat disembuhkan dan pasien tanpa gangguan organ $100 \%$ sembuh.

Tabel 3. Hubungan Jumlah Organ dengan Outcome Pada Pasien Malaria Falciparum Berat yang Dirawat Inap di RSUP M. Djamil Padang pada Januari 2010 sampai Desember 2013

\begin{tabular}{lrrrrrrl}
\hline \multirow{2}{*}{$\begin{array}{l}\text { Jumlah } \\
\text { Organ }\end{array}$} & \multicolumn{2}{c}{ Outcome } & \multicolumn{3}{c}{ Total } & \multirow{2}{*}{$\mathbf{p}$} \\
\cline { 2 - 6 } & $\mathbf{n}$ & $\%$ & $\mathbf{n}$ & $\%$ & $\mathbf{n}$ & $\%$ & \\
\cline { 2 - 6 } & & & & & \\
\hline 1 organ & 9 & 100 & 0 & 0 & 9 & 100 & \\
2 organ & 2 & 100 & 0 & 0 & 2 & 100 & 0,02 \\
3 organ & 0 & 0 & 1 & 100 & 1 & 100 & \\
\hline
\end{tabular}

Pada tabel 2 didapatkanada Hubungan Jumlah Organ dengan Outcome (nilai $p=0,02$ ), artinya, semakin meningkat jumlah organ yang dikenai, maka angka mortalitas juga meningkat. Pada penelitian ini, pasien yang mengalami gangguan satu organ dan dua organ masih dapat disembuhkan, sedangkan pasien yang mengalami gangguan tiga organ meninggal.

\section{PEMBAHASAN}

Berdasarkan penelitian yang dilakukan terhadap pasien Malaria Falciparum Berat yang dirawat di RSUP Dr. M. Djamil Padang, didapatkan 13 data pasien yang memenuhi kriteria untuk dijadikan sampel pada penelitian ini. Berdasarkan uji chi square, terdapat hubungan yang bermakna antara adanya gangguan organ dengan prognosis, nilai $p=0,003(p$ $<0,05)$. Maknanya penderita malaria falciparum berat dengan gangguan organ akan mengalami prognosis yang buruk,

Dalam penelitian ini, pasien malaria falcibarum berat dengan gangguan organ otak, hati, limpa dan ginjal, dengan gangguan satu jenis organ atau lebih, akanmengalami prognosis yang buruk.

Prognosis penderita malaria falciparum berat akan lebih baik bila penderita sudah ditangani dalam 48 jam sejak masuk ke stadium malaria berat. ${ }^{6}$

Berdasarkan uji statistik mengenai hubungan antara adanya gangguan organ dengan outcome (sembuh atau meninggal), didapatkan hubunganya tidak bermakna dimana nilai $p=1,000(p>0,05)$. Maknanya penderita dengan gangguan organ tidak selalu meninggal atau dapat disembuhkan.Hal ini dimungkinkan karena adanya faktor-faktor lain yang mempengaruhi prognosis dan outcome seperti kecepatan penderita tiba dirumah sakit sehingga penderita juga cepat mendapatkan diagnosis yang tepat dan penanganan yang akurat. Sejak tahun 2006, WHO telah merekomendasikan pengobatan malaria dengan menggunakan obat ACT (Artemisin base Combination Therapy) sebagai lini pertama pengobatan malaria, baik malaria tanpa komplikasi atau malaria berat. Dari hasil penelitian yang dilakukan di Rumah Sakit umum Bethesda Serukam juga didapatkan bahwa pengobatan dengan derivat artemisinin dapat menurunkan lama demam, lama perawatan, angka mortalitas pada pasien dibandingkan dengan penggunaan kina. ${ }^{2,7}$

Hubungan Jenis Organ dengan Outcome tidak dapat diketahui karena hasilnya konstan, dimana pasien malaria falcibarum berat dengan gangguan 
organ otak dan hati keluar dalam keadaan sembuh (Outcome sembuh), artinya penderita yang mengalami malaria billiosa saja atau malaria serebral saja, masih dapat disembuhkan.Dalam literature menyebutkan bahwa angka kematian malaria serebral $10-20 \%$, sedangkan pada penderita malaria serebral yang disertai koma dan kejang angka kematian dapat mencapai $80 \%$. Penderita dengan kelainan fungsi hati atau malaria billiosa angka kematian bervariasi dan meningkat seiring dengan penurunan fungsi hati yang dapat dilihat dari peningkatan kadar bilirubin total dan SGOT/SGPT. Angka mortalitas tinggi mencapai 33\% bila bilirubin total $>3 \mathrm{mg} \%$ dan SGOT/SGPT meningkat $>3 x$ normal. $^{2,6}$

Berdasarkan uji chi square terhadap hubungan jumlah organ dengan outcome (sembuh atau meninggal), didapatkan hubungan yang bermakna, dimana nilai $p=0,02(p<0,05)$. Maknanya penderita dengan gangguan satu dan dua organ lebih baik dibandingakan yang mengenai tiga organ, dimana penderita dengan gangguan tiga organ meninggal. Penderita yang meninggal adalah penderita yang mengalami malaria serebral yang diikuti dengan kegagalan dua organ lainya yaitu hati dan ginjal.Sesuai dengan literatur bahwa prognosis malaria berat dengan kegagalan satu fungsi organ lebih baik dari pada kegagalan dua fungsi organ atau lebih. Mortalitas pada kegagalan tiga fungsi organ $>50 \%$ dan kegagalan lebih dari empat organ mencapai $75 \%$ atau lebih. ${ }^{4}$ Sejalan dengan penelitian di Minahasa, penderita malaria serebral yang disertai dengan kegagalan dua organ angka mortalitas $47,6 \%$ dan dengan kegagalan tiga organ angka mortalitas mencapai $88,9 \%{ }^{2}$

Penderita yang meninggal (dalam penelitian ini) tidak hanya mengalami kegagalan tiga organ, tetapi juga memiliki faktor lainya yang memperburuk prognosis dan meningkatkan angka mortalitas yaitu mengalami banyak komplikasi seperti anemia berat ( $\mathrm{Hb} 4 \mathrm{mmol} / \mathrm{L})$, leukositosis $(15.200 / \mu \mathrm{L})$ dan hiperparasitemia $(400.000 / \mu \mathrm{L})$ dan merupakan pasien rujukan, dimana pasien dirujuk ke RSUP M. Djamil Padang sudah dalam keadaan yang sudah cukup parah. Penderita terlambat mendapatkan penangan dan pengobatan yang tepat sehingga parasit telah menyebar dan menyerang organ tubuh lainnya dengan cepat.

Sedikitnya jumlah sampel pada penelitian ini dan juga data yang diambil hanya berasal dari 1 rumah sakit, sehingga sampel penelitiannya tidak mewakili seluruh populasi.Selain itu, data rekamedis tidak lengkap, ada beberapa hasil pemeriksaan yang hilang atau tidak dituliskan pada status pasien, sehingga mempengaruhi hasil penelitian ini.

Penelitian ini juga tidak memperhitungkan faktor-faktor lain yang mempengaruhi prognosis dan outcome, seperti waktu (kapan penderita dibawa ke rumah sakit) dan diagnosis serta penatalaksanaan (kecepatan dan ketepatan diagnosis dan penatalaksanaan di rumah sakit).Meskipun data yang mendukung faktor tersebut ada di dalam catatan rekam medis, karena keterbatasan peneliti sehingga tidak dilakukan penelitian terhadap faktor-faktor tersebut.

Meskipun penelitian ini memiliki keterbatasan, namun diharapkan tetap dapat memberikan manfaat dalam upaya pendeteksian dan penatalaksanaan dini terhadap kasus malaria falciparum berat dengan gangguan organ sehingga prognosisnya baik dan keluar rumah sakit dalam keadaan sembuh (outcome sembuh). Selain itu, penelitian ini diharapkan dapat memberikan ide dan dapat menjadi pembanding bagi penelitian selanjutnya.

\section{KESIMPULAN}

Berdasarkan penelitian yang telah dilakukan, dapat diambil kesimpulan bahwa jumlah pasien malaria falciparum berat yang dirawat dan tercatat di bagian rekam medis RSUP M. Djamil Padang periode Januari 2010 sampai Desember 2013 adalah 13 orang, dimana lebih dari setengahnya $(53,8 \%)$ adalah perempuan dengan umur berkisar 26-45 tahun (kategori dewasa). Pada pasien malaria falciparum berat, sebagian besar mengalami gangguan organ dengan persentese $92,3 \%$. Jenis organ yang paling banyak dikenai adalah hati, jumlah organ yang mengalami gangguan organ paling banyak adalah mengenai satu organ dan masih terdapat pasien dengan gagal tiga organ.Sebagian besar pasien 
malaria berat memiliki prognosis buruk, namun sebagian besar pasien malaria berat keluar dalam keadaan sembuh (outcome sembuh). Terdapat hubungan antara adanya gangguan organ dengan prognosis, Pasien malaria falcibarum berat dengan gangguan organ otak, hati, limpa dan ginjal, dengan gangguan satu jenis organ atau lebih, akan mengalami prognosis yang buruk. Tidak terdapat hubungan antara adanya gangguan organ dengan outcome, Pasien malaria falcibarum berat dengan gangguan organ otak dan hati keluar dalam keadaan sembuh (Outcome sembuh), Terdapat hubungan antara jumlah organ dengan outcome.

\section{DAFTAR PUSTAKA}

1. Kementrian Kesehatan RI. Profil Data Kesehatan Indonesia Tahun 2011. 2012 (diunduh 15 Maret 2013). Tersedia dari: URL: HYPERLINK http://www.depkes.go.id/downloads/profil data ke sehatan indonesia tahun 2012.pdf

2. Harijanto PN. Tatalaksana Malaria Berat. Edisi ke-
2. Jakarta: Buku Kedokteran ECG; 2008.

3. Morrow R. Epidemiology and Control of Malaria. Johns Hopkins Blooberg School and Public Healt. 2007 (diunduh15 Oktober 2013). Tersedia dari:URL:HYPERLINKhttp://ocw.jhsph.edu/course s/EID lec17 morrow.pdf

4. Departemen Kesehatan RI. Pedoman Penatalaksanaan kasus malaria di Indonesia. Ditjen PP-PL. Jakarta: Depkes RI; 2008.

5. Harijanto PN. Presentasi Klinis Malaria Berat. Edisi ke-2. Jakarta: Buku Kedokteran ECG; 2008. HIm. 224-6.

6. Sutanto I, Ismed IS, Sjarifuddin PK, Sungkar S. Parasitologi Kedokteran. Edisi ke-2. Jakarta: Balai Penerbit FKUI; 2009.

7. Darnindro N, Halim Y, Sajuni. Studi Retrospektif pada Pasien Malaria Falciparum dengan Komplikasi pada Rumah Sakit Umum Bethesda Serukam Periode Tahun 2007-2008.Majalah Kedokteran Indonesia, 2010;60(1):22-6. 